\title{
THE GLYPHIC TEXTS AT AGUATECA ${ }^{1}$
}

\author{
Steven S. PERry \\ Washington University
}

The five legible stelae (numbers 1, 2, 3, 5, and 7) at Aguateca span a period of five katuns from 9.13.0.0.0 to 9.18.0.0.0. Eight (numbers 4,6 , and 8-13) other illegible, shattered, plain, and non-glyphic stelae are also present at the site. The texts on the four most legible stelae (numbers 1, 2, 3, and 7) contain twelve event glyph blocks discussing a limited number of this. Of the twelve event glyph blocks not more than five and possibly only four events are involved.

Only the two event glyphs dealing with accession can be readily identified; they appear on Stela 1 (fig. 1, A7 and B12). The binding on the event glyph at A7 is indicative of an accession (Proskouriakoff, 1960). From Schele (1978: 7) the event glyph at B12 can be further specified as an inauguration glyph. The same name clause (fig. 1, A8b-A10 and A13-A14) follows both event glyphs with a twenty-two day Secondary Series (fig. 1, A11) intervening. The short passage of time accompanied by this double statement of accession most likely records the actual accession and the official ceremony. This glyphic text supports Schele's inauguration interpretation for the glyph found at $\mathrm{B} 12$.

The name clause following the accession glyphs occurs one other time on Stela 1 (fig. 1, D3-D5). This name consists of three glyph groups. It begins with a T1030c glyph (a title or honorific; Proskouriakoff in Graham, 1967: 9) followed by a postfix which Schele calls Mah K'ina, a religious personage and royalty associated glyph group (Schele, 1978: 26). This is followed by a glyph group containing a "capture" glyph (T764a) wich does not function here as a "capture" glyph but rather as part of an individual's name. The benich (ah-po) superfix which follows indicates the station of the per-

1 I wish to thank Dr. Marshall Durbin for his patient editing and David Doty and Neal Siegel for proofreading this paper. 
sonage named by the Turtleshell main sign. It ends with an unusual glyph block containing two glyph groups: the first contains Schele's (1978: 11) "ah" ("he of" T12) above a coefficient of two above the Palenque main sign (T570) located next to an Aguateca emblem glyph (fig. 1, A10, A14, and D5).

The Palenque main sign is employed in these three name clauses and one other on Stela 7 (fig. 6, C1.D2). On Stela 7 the Palenque main sign has a coefficient of three instead of two as in its Stela 1 appearance (fig. 1, A10, A14, and D5). The significance of this is not known. This fairly rare use of two emblem glyph elements within a name clause might be interpreted as "he from Palenque, ruler of Aguateca". It is also found $(\mathrm{T} 12 ; 570)$ at Seibal on Stela 5 with a superfix coefficient of 2 .

The remaining ten event glyph meanings are unclear. Five of these event glyphs - two on Stela 1 (fig. 1, A2 and D2b), one on Stela 2 (fig. 2, G3), one on Stela 5 (fig. 5, G3) and one event glyph on Stela 3 (fig. 4, A3b) contain many of the same elements. These five glyph groups are all assumed to discuss the same event. Four of these five event glyphs consist of the hand (T710) main sign, the smoke-and-fire affix (T93), and the T136 affix. Only the respective position of the glyphic elements varies slightly. The uniformity of these glyph blocks makes it likely that only one event is being recorded. The glyph group on Stela 3 (fig. 4, A3b) is grouped with these glyphs as it contains all of the same elements except the smoke-and-fire affix which might possibly be present in the next glyph at C3. ${ }^{2}$ Ian Graham (1967: 9) contains a note of Proskouriakoff's stating that this glyph block probably deals with prophecy or divination. This interpretation seems more probable than the common suggestion of grain scattering, at least for agricultural purposes, because the dates associated with the event glyphs do not fall within the same season. This same configuration (T710: 93) is also found at Dos Pilas on Stela 1 (A4) and Stela 17 (B3).

Another glyph block occurring more than once also contains the hand (T710) main sign. ${ }^{3}$ It is found on Stela 1 (fig. 1, D6), on Stela 2 (fig. 2, F4), and on Stela 7 (fig. 6, E2). The use of the T710 main sign here and also in the event glyph discussed above could be suggestive of a similarity in the event being recorded.

The two still undiscussed event glyphs are unique in their appearances. Much of an event glyph on Stela 1 (fig. 1, A5) has been eroded

2 El autor tiene C3 pero debe ser B3 (M. A. F.).

3 El glifo al que alude el autor es más parecido a T671 (M. A. F.). 
but from what remains legible it is obvious that it is not repeated elsewhere. Stela 2 (fig. 2, D1) contains the last event glyph to be discussed here and is followed by a name clause. This event glyph and name clause also appears on Stela 16 at Dos Pilas (fig. 3, D2). These two stelae, at Aguateca and Dos Pilas, appear to be commemorating the same event as noted by Graham (1967: 9).

The Aguateca material also contains some interesting items. In the Secondary Series the glyph used for the kin sign is an inverted Ahau. Such usage of the inverted Ahau is noted by Berlin (1964: 4) at other sites. It appears as such on Stela 1 (fig. 1, A6a and B14) and on Stela 2 (fig. 2, B2a and C2). It is also used in the Secondary Series of Stela 16 at Dos Pilas (fig. 3, D1 and D6), the stela discussing the same event as Aguateca Stela 2. As Neuenswander (1980) has noted, Ahau is the equivalent of hin in Cubulco Achi, a highland Mayan language. The typical uinal glyph (fig. 1, A11a) is employed in another Secondary series on Stela 1.

The glyph block on Stela 2 (fig. 2, A2 and also found at Dcs Pilas, Stela 2) often identified in this position as an event glyph serves another function here. It is unusual because its main element is a triple cauac which also serves as the main sign in the Seibal emblem glyph found later in the text (fig. 3, F3). Schele's era event identification (1978: 17) for a similar glyph block does not seem pertinent in this usage as there is no further reference to 13.0.0.0.0 4 Ahau 8 Cumku.

Stela 1 (fig. 1, D10) and Stela 2 (fig. 2, G6) use an unusual cauac derivative. In the text it is associated with Schele's Mah K'ina which seems to have some connection with religious personage or royalty. In both cases it is followed by a scroll (T856, fig. 1, D10b and Fig. 2, G7a). This scroll forms a headdress at Yaxchilan, Lintel 3 (Graham, 1967: 8). The individual at Yaxchilan portrayed wearing the headdress seems to be Bird Jaguar. Such similarity could be the result of a reference to Bird Jaguar or to his title.

The first name that appears on Stela 7 (fig. 6, C1-D2) contains a three ben-ich katun (fig. 6, C2). From Marshall Durbin (Manuscript) this glyph group can be read as a class of warrior i.e. Jaguar-paw warrior. The middle element of the second name clause (fig. 6, E2) referred to by Ian Graham (1967: 25) as water-bird god bears a striking resemblance to a bird in the headdress of a figure (possibly a prisoner) paying homage, in the lower left corner, on Stela 2 at Machaquila (fig. 7). This might possibly be a reference to the figure paying homage. 
Although at first glance the glyphic material at Aguateca appears to contain much textual material this is not the case. Most of the glyphic material is made up of dates, Secondary Series, and names. However, the site lacks legible lunar or nocturnal series. The glyphic text consists only of the event glyph followed by a name. This indicates that Aguateca, in comparison with other sites, seems not to have possessed the glyphic writing tradition to a very high degree of sophistication.

\section{REFERENCES}

Berlin, Heinrich

1964 "El Glifo 《otz Invertido»", Antropología e Historia de Guatemala, XVI, No. 1.

Durbin, Marshall

1979 Aspects of Glyphic Readings at Yaxchilan. Manuscript.

Graham, IAN

1967 Archaeological Explorations in El Peten, Guatemala. Middle American Research Institute, Tulane University. New Orleans.

Merle, Greene, Robert L. Rands, and John A. Graham

1972 Maya Sculpture. Lederer, Street and Zeus, Berkeley, California. Neuenswander, Helen

Vestiges of Early Maya Time Concepts in a Contemporary Maya (Cubulco Achi) Community: Implications for Epigraphy. Presented at the 77th. Annual Meeting of the American Anthropological Association.*

Proskouriakoff, Tatiana

1960 "Historical Implications of a Pattern of Dates at Piedras Negras, Guatemala". American Antiquity, 25: 454-475. Salt Lake Schele, Linda City.

1978 Maya Hieroglyphic Writing Workshop. Institute orf Latin American Studies. The University of Texas at Austin. Austin, Texas. Thompson, J. ERic S.

1970 A Catalog of Maya Hieroglphs. University of Oklahoma Press. Norman.

* Este trabajo se edita en este mismo volumen, p. 125-163. 


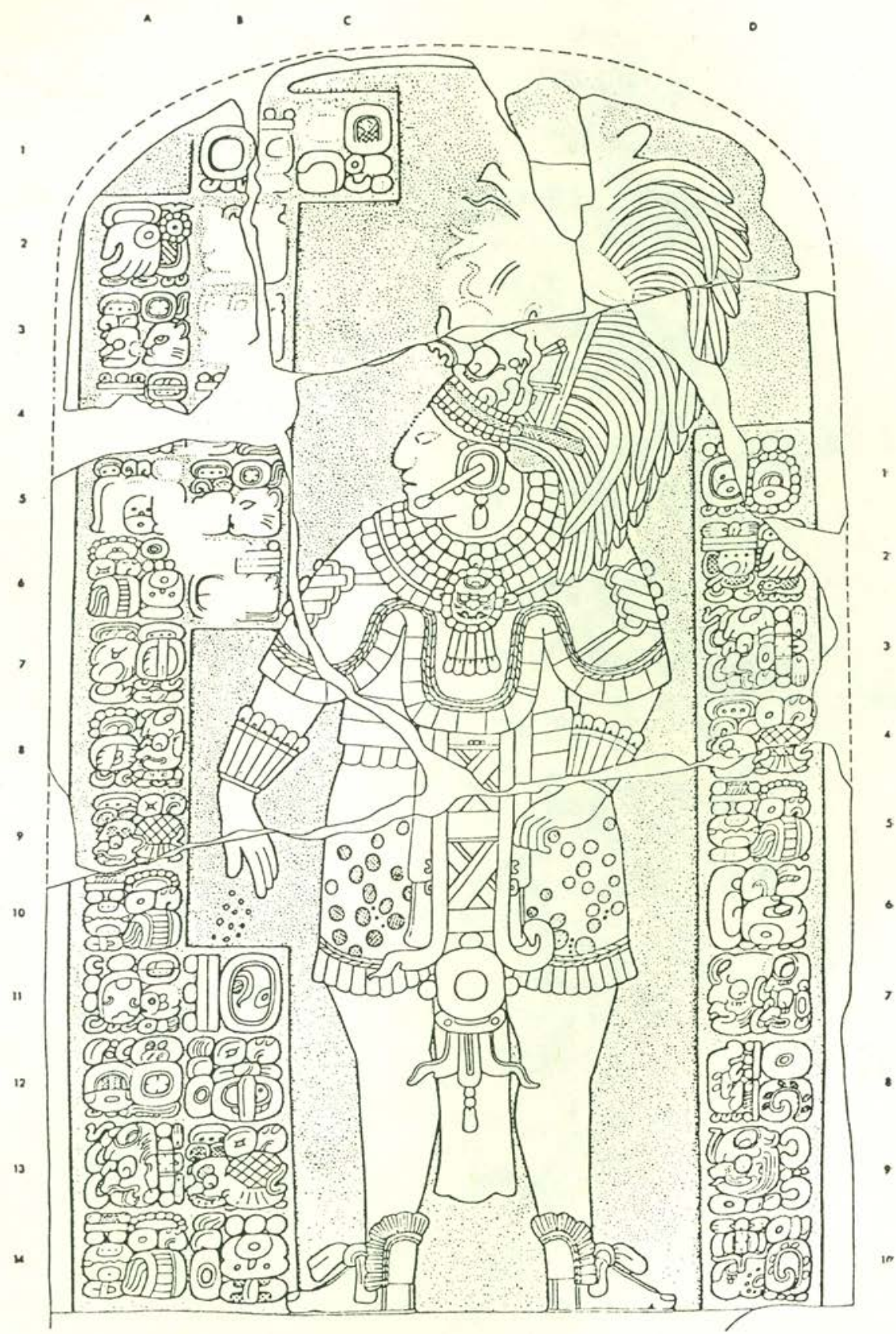

FiC. J - AGUATECA, STELA I

(From Graham: 1967) 


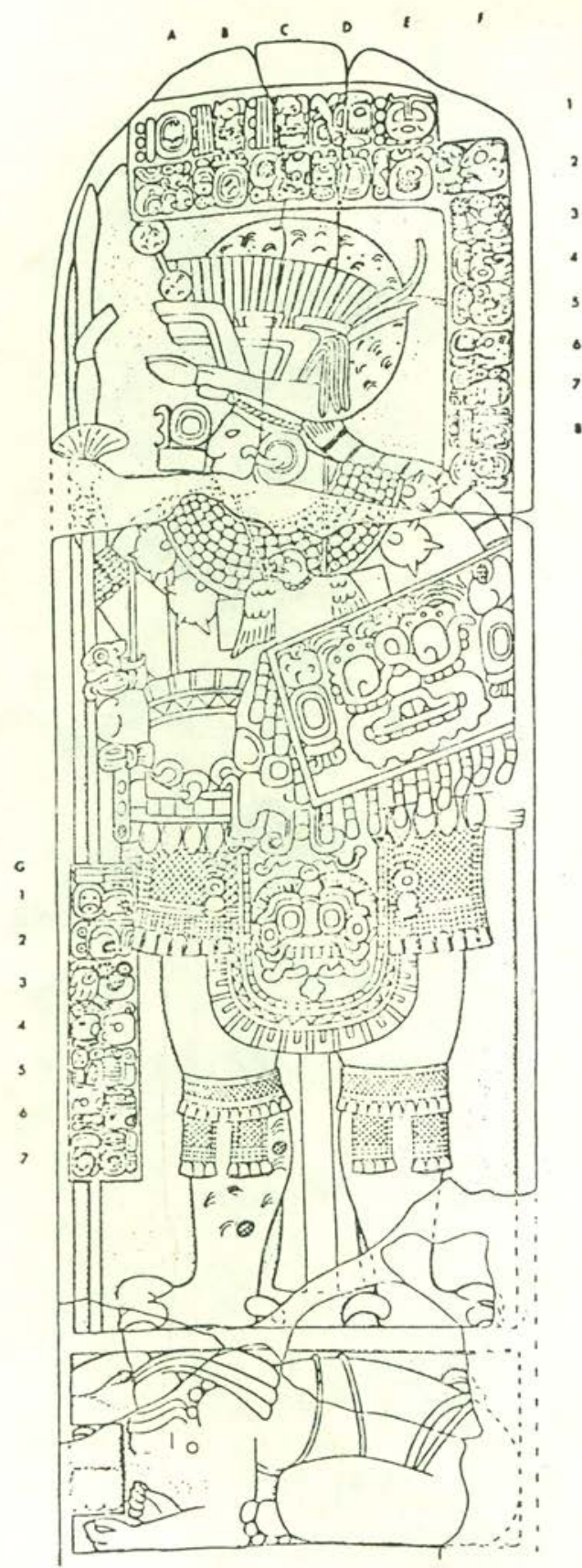

FiC. 2-ACUATECA, STELA 2

(From Graham: 1967)

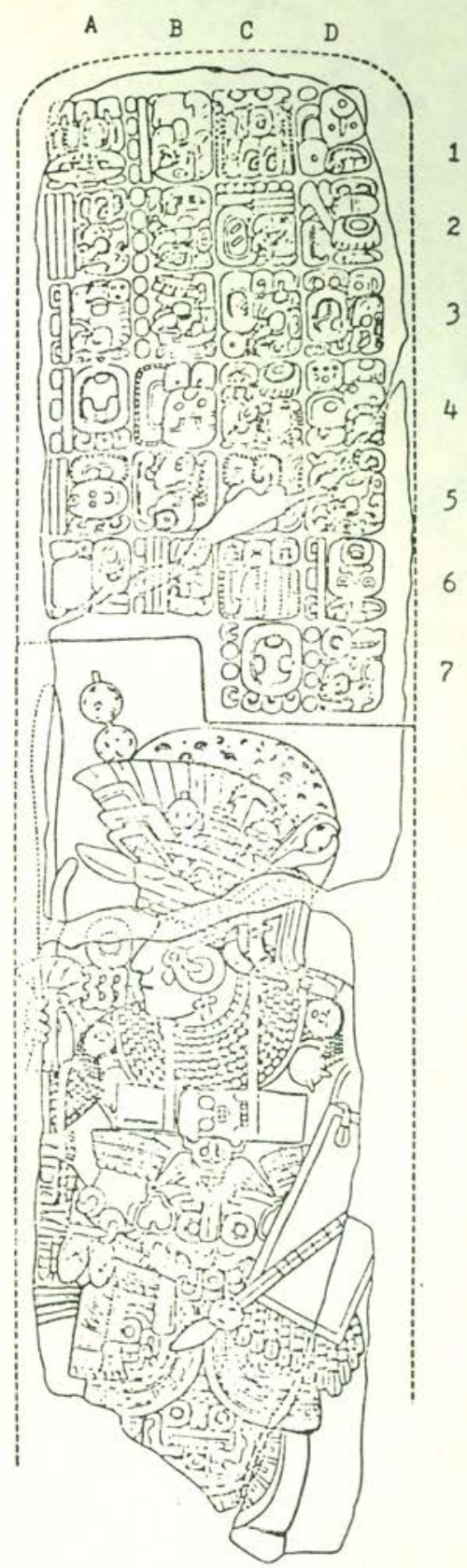

FIC 3-DOS PILAS, STELA 16

(From Craham: 1967) 


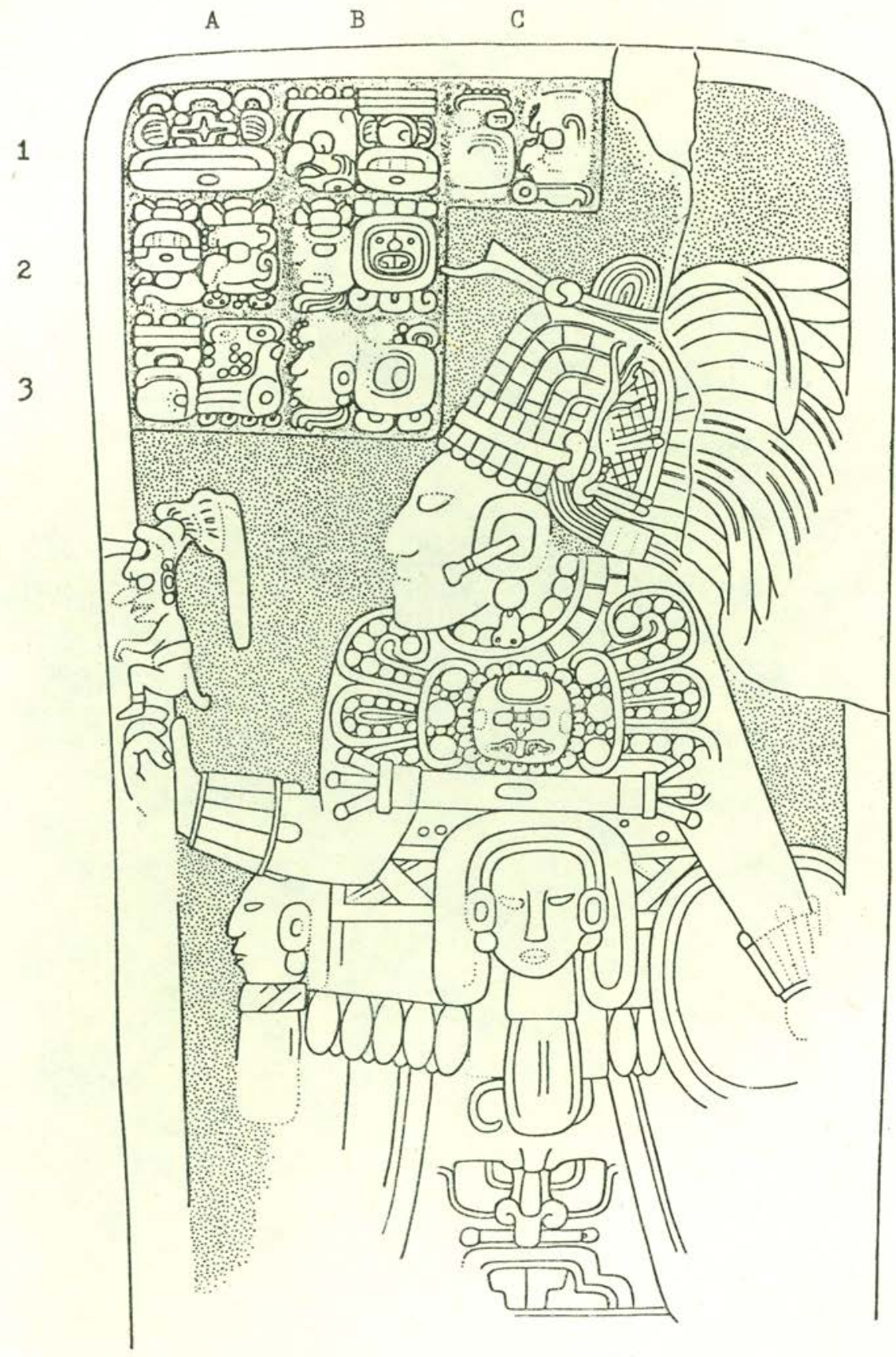

FIC.

(From Graham: 1967) 

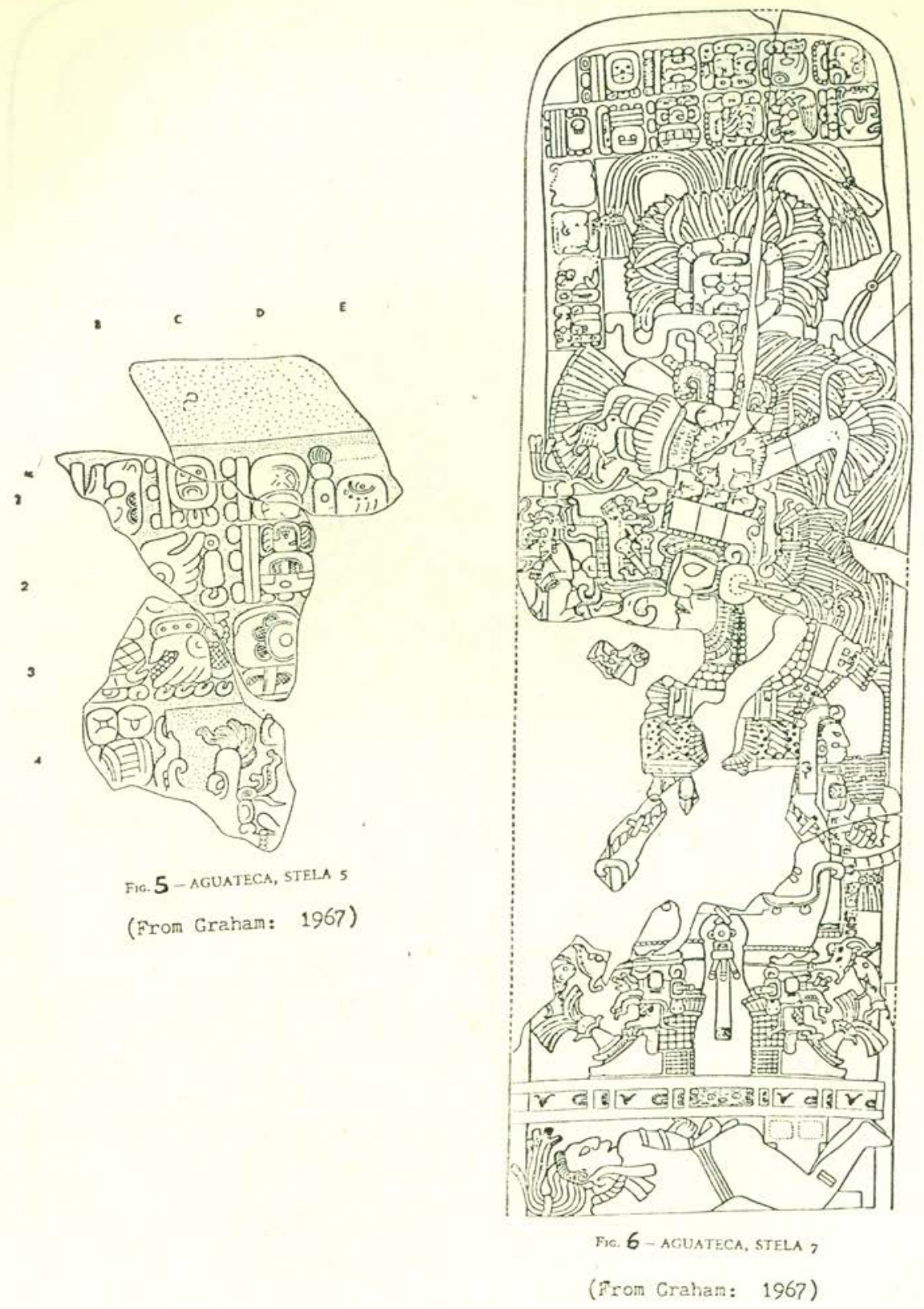

Estudios de Cultura Maya. Vol. XIII, 1981

Instituto de Investigaciones Filológicas/

Centro de Estudios Mayas, UNAM 


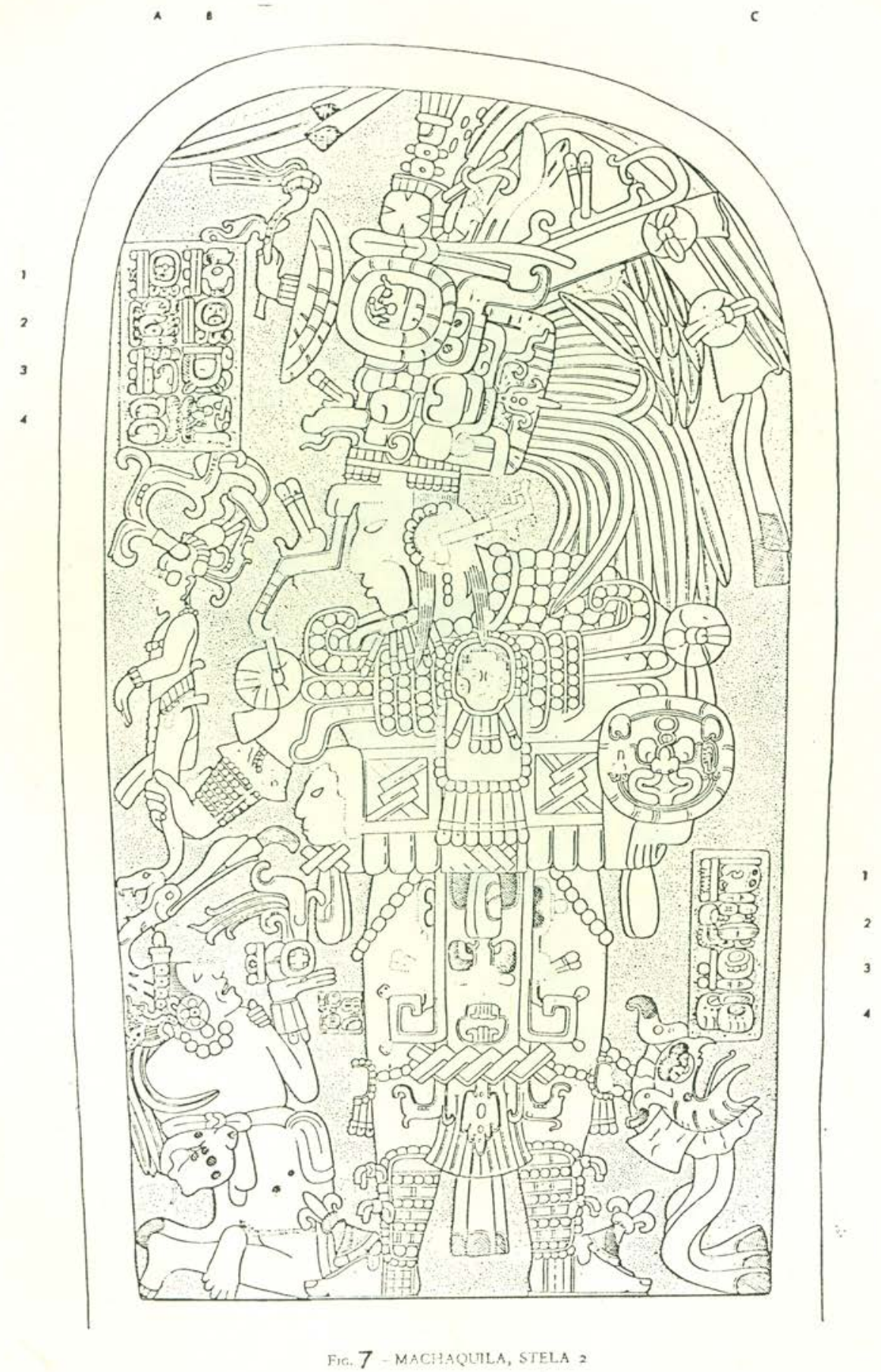

(Froin Craham: 1967) 